\title{
ANÁLISE DE EVENTOS DE RISCOS NO NEGÓCIO DE MANUTENÇÃO DE NAVIOS PETROLEIROS
}

\author{
AN ANALYSIS OF RISK EVENTS IN THE \\ OIL-TANKER MAINTENANCE BUSINESS
}

Recebido 05/07/2012

Aceito 06/11/2012

Roque Rabechini Jr. ${ }^{1}$ José Eduardo Modica²

\section{RESUMO}

Este trabalho apresenta os resultados de uma investigação sobre eventos de risco e suas respectivas causas, realizada em empreendimentos de manutenção de navios do setor de logística da indústria petrolífera brasileira. Seu posicionamento teórico conceitual se encontra nos aspectos relacionados ao gerenciamento de riscos de empreendimentos, como instrumentos de apoio à tomada de decisão pelos executivos do negócio de manutenção de navios petroleiros. Utilizou-se, como alternativa metodológica, o estudo de caso com uma abordagem qualitativa de caráter exploratório e, para a apresentação dos dados, optou-se por fazer de forma descritiva. Pela análise de 75 eventos de riscos de projetos de docagem de navios petroleiros foi possível extrair os oito de maior relevância. A análise dos riscos possibilitou identificar ações que contemplassem sua mitigação. Como conclusão, foi possível propor um modelo de enquadramento dos riscos em quatro categorias, sms - saúde, meio ambiente e segurança -, técnico, externo e de gerenciamento, visando dar aos executivos e administradores do negócio de docagem de navios petroleiros, evidências de ações para subsidiar seu processo de tomada de decisão. Por fim, os autores identificaram as proposições para novos estudos, bem como mostraram as principais limitações do trabalho.

Palavras-chave: Gerenciamento de riscos, docagem.

\footnotetext{
${ }^{1}$ Doutorado em Engenharia de Produção pela Escola Politécnica da Universidade de São Paulo, Professor Titular da Universidade Nove de Julho, São Paulo - SP, Brasil. E-mail: roquejr@uninove.br.

${ }^{2}$ Possui graduação em Engenharia Civil pela Fundação Armando Álvares Penteado, Especialização em Curso de Especialização Em Administração de Empresas pela Universidade de São Paulo, São Paulo - SP, Brasil. E-mail: eduardomodica@gmail.com.
} 


\section{ABSTRACT}

This work presents the results of an investigation into risk events and their respective causes, carried out in ship maintenance undertakings in the logistical sector of the Brazilian oil industry. Its theoretical, conceptual positioning lies in those aspects related to risk management of the undertakings as instruments of support in decision making by executives in the tanker-maintenance business. The casestudy method was used as an alternative methodology with a qualitative approach of an exploratory nature and, for the presentation of data, a descriptive format was chosen. Through the analysis of 75 risk events in projects of tanker docking it was possible to extract eight of the greatest relevance. The risk analysis facilitated the identification of actions aimed at their mitigation. As a conclusion it was possible to propose a risk-framework model in four categories, HSE (health, safety and the environment), technicians, externalities and management, designed to provide tanker-docking business executives and administrators, with evidence of actions to assist in their decision-making processes. Finally, the authors identified proposals for further study as well as showing the principal limitations of the study.

Keywords: Risk management, docking

\section{INTRODUÇÃO}

O gerenciamento de riscos em projetos tem se tornado uma disciplina de intenso interesse aos executivos e administradores de empresas principalmente devido às influências ocorridas pela crise mundial de 2008. Um dos setores que mais sofreu com seus impactos, foi o petrolífero, com a sensível queda dos preços do barril de petróleo. Administrar rigorosamente empreendimentos relacionados tornou-se um desafio cada vez mais relevante no cenário mundial. Neste sentido, uma das principais preocupações dos profissionais de projetos tem sido, especificamente, com a sua gestão e em particular, com a efetividade do gerenciamento de riscos (AKINTOYE e MACLEOD, 1997).

A preocupação com gerenciamento de riscos tornou-se mais evidente, para a comunidade de gerenciamento de projetos, após a publicação da pesquisa de Ibbs e Kwak (2000), em que foi reconhecida esta área de conhecimento como sendo a mais carente em termos gerenciais, examinados em três dos quatro setores econômicos estudados (CARVALHO e RABECHINI, Jr., 2005; SALLES, et al, 2006).

Entender as raízes destas preocupações requer estabelecer um quadro teórico / conceitual da disciplina gerenciamento de risco, para que se possam caracterizar as bases das principais abordagens a respeito do assunto. Um quadro conceitual que leve em conta pelo menos dois caminhos de interesse, de um lado os estudos sobre a natureza dos riscos e, de outro os de caráter prático.

$\mathrm{Na}$ linha dos estudos da natureza dos riscos e seus aspectos conceituais, destacam-se os trabalhos de Wideman (1992), Bernstein (1998), Meyer et al (2002) e Perminova et al (2008). Fundamentalmente, eles tratam dos aspectos do risco e as relações com incertezas, dos efeitos e suas implicações para os resultados do projeto, das ambigüidades e variabilidades, entre outros assuntos que constituem as bases do conhecimento e os alicerces do tema em questão. Enquanto Bernstein (1998) apresenta um rico enquadramento histórico do risco e sua importância para os gerentes de projetos, Meyer et al (2002) discutem os aspectos da variabilidade e ambigüidades. Nesta linha de estudos, destaca-se ainda, o trabalho de Ward e Chapman (2003) com uma proposição singular, que enfatiza o gerenciamento das incertezas como substituto para o gerenciamento de riscos, pois apresenta uma abordagem mais ampla sobre o assunto.

Outra corrente de trabalhos em gerenciamento de riscos em projetos liderados pelo PMI (2004) dá ênfase nos aspectos práticos, em que o processo gerencial se faz relevante do pon- 
to de vista das aplicações nas organizações. Destacam-se, nesta linha de estudos, os trabalhos de Hillson (2001), , Raz et al. (2002), além de Wideman (1992) que, de uma forma ampla, têm desenvolvido trabalhos nas duas linhas aqui mencionadas. No bojo das abordagens propostas por esta corrente de pensamento destacam-se, predominantemente, os trabalhos que tratam das técnicas e ferramentas desenvolvidas para serem aplicadas no gerenciamento de risco. Ancoradas em práticas freqüentemente adotadas por empresas que se interessam em gerenciar os eventos incertos nos projetos, os trabalhos aqui mencionados refletem a visão dos riscos sob diversas perspectivas. Uma delas (HILLSON, 2001) propõe discutir alternativas para riscos tanto sob o ponto de vista negativo ou de ameaça, mas também sob o ponto de vista positivo ou oportunidades. Outra (RAZ et al, 2002), identifica a importância dos processos de gerenciamento de riscos para setores distintos.

Estes dois caminhos mostram a evolução do pensamento do gerenciamento de riscos em projetos atualmente. Mas o interesse por gerenciamento de riscos em projetos é, de certa forma, decorrente do interesse por gerenciamento de projetos lato sensu e se concentra nos anos 90's, o período de notável crescimento.

Dadas considerações acima, este trabalho visa explorar a priorização de riscos, conseqüência de um processo gerencial de projetos de manutenção de navios petroleiros. Para isto, desenvolveu-se uma pesquisa com profissionais envolvidos em projetos desta natureza visando entender a importância do gerenciamento de riscos.

Para nortear estes objetivos criou-se a seguinte questão de pesquisa: como a estruturação de respostas a riscos relevantes em projetos de manutenção de navios petroleiros pode subsidiar a decisão de seus executivos?

A partir da questão foi possível entender os aspectos de gerenciamento de riscos condizentes a um projeto de docagem de navios petroleiros. Os resultados aqui apresentados evidenciam que as práticas de gerenciamento de riscos são pouco utilizadas e que, seu uso poderá aumentar as chances de sucesso desses projetos.

Após esta introdução serão apresentados os fundamentos teóricos no próximo capítulo, em que serão discutidos os aspectos relevantes da análise dos eventos de riscos em projetos de manutenção de navios petroleiros. Para isto, serão apresentadas, conforme a literatura especializada, as principais características deste tipo de projeto. Na seqüência, as considerações metodológicas deste estudo serão discutidas. A seguir, passa-se ao capítulo referente à apresentação dos resultados e suas respectivas análises. Por fim, as considerações serão tecidas, levando-se em conta as limitações encontradas no desenvolvimento desta pesquisa, bem como serão propostas as prospecções de futuras pesquisas.

\section{Fundamentos teóricos}

Um paradoxo do gerenciamento de riscos tem despertado interesse e curiosidade na comunidade de gerenciamento de projetos: de um lado esta área de conhecimento é uma das mais importantes e repletas em técnicas e ferramentas, de outro, é uma das mais carentes de estudos. Uma pesquisa conduzida por Ibbs e Kwak (2000) mostrou que a falta de intimidade para lidar com incertezas está presente em gerentes de projetos de quatro setores distintos pesquisados: telecomunicações, manufatura de produtos de alta tecnologia, tecnologia de informação e engenharia de construção. Absorver os conceitos de riscos, incertezas e saber como gerenciá-los, acredita-se, é uma das principais considerações que gerentes de projetos podem extrair da pesquisa. 
Uma das mais valiosas contribuições ao entendimento dos conceitos de risco foi dada por Wideman (1992) ao configurar os limites do campo das incertezas, incluindo antagonicamente os elementos do desconhecido e certeza. A incerteza, neste aspecto, pode ser considerada um campo conceitual delimitado entre esses dois elementos, que vem a ser o centro das preocupações dos estudos de riscos. A relação risco versus incerteza adotada pelo PMI (2004), por exemplo, considerou esta relação, estabelecendo uma definição de risco abrangente como sendo "um evento ou condição incerta que, se ocorrer, tem um efeito positivo ou negativo nos objetivos do projeto".

Neste aspecto, os riscos em projeto têm sua origem no campo das incertezas que, por sua vez, está presente, de uma forma mais ou menos intensa, em todos os projetos (PERMINOVA et al, 2008).

Para Perminova et al (2008) a principal diferença entre risco e incerteza se refere à possibilidade do estabelecimento de probabilidade do evento. Assim, o risco caracteriza-se por uma situação cuja decisão é tomada sob condições de probabilidades conhecidas. Já, incertezas não. É impossível associar a elas valores de probabilidades numéricas, bem como há falta de conhecimentos sobre as conseqüências de um evento.

Um aspecto bastante interessante das incertezas, aderente e ao mesmo tempo complementar aos estudos de Wideman (1992) e que apresenta uma visão mais ampla do assunto, foi dado por Meyer et al (2002), que propuseram quatro tipos de incertezas:

1. Variabilidade: variações aleatórias, porém previsíveis e controláveis em torno de seus objetivos conhecidos de custo e prazo;

2. Incerteza previsível: Uns poucos fatores conhecidos irão afetar o projeto de uma forma imprevisível permitindo, entretanto, que sejam estabelecidos planos de continência para tratar das conseqüências de seu eventual acontecimento;

3. Incerteza imprevisível: um ou mais fatores significativos que influenciam o projeto não podem ser previstos obrigando a solução de problemas na ocorrência desses;

4. Caos: fatores completamente imprevisíveis invalidam completamente os objetivos, o planejamento e a abordagem do projeto, obrigando a sua repetida e completa redefinição.

Conceitualmente, o campo das incertezas pode ser visto, como sendo o centro das preocupações do gerenciamento. Neste aspecto, Ward e Chapman (2003) argumentam que todo o processo de gerenciamento de riscos em projetos deve restringir seu foco na administração de incertezas, uma vez que o risco está sempre associado a ameaças (ou oportunidades) de eventos incertos aos projetos.

Em um estudo anterior, Ward e Chapman (2003) mostraram que as formas tradicionais de tratamento ao risco tendem a se concentrar nos eventos de variabilidade e pouco considera os aspectos da ambigüidade existentes nos projetos. Para eles variabilidade se refere aos elementos de um projeto que podem assumir valores distintos, portanto incertos, como: prazos, custos e qualidade. Já ambigüidade está associado a falta de clareza nos dados, nos detalhes, estruturas, entre outros, pois no comportamento dos envolvidos estão presentes vieses, conhecimentos restritos e situações não claras.

O trabalho de Ward e Chapman (2003) pode ser visto como um continuum que representa o espectro do gerenciamento das incertezas considerando não só as ameaças como também, as oportunidades. A visão ampliada de riscos, envolvendo ameaças e oportunidades, foi 
corroborada pelo trabalho de Hillson (2001). Para ele riscos estão relacionados a eventos incertos que podem afetar os objetivos de um projeto negativa ou positivamente. Esta forma de posicionar o risco gera estratégias de administração distintas.

Para o departamento de defesa norte-americano (DOD, 2006), risco é entendido como uma medida das futuras incertezas em se atingir os objetivos do programa dentro de suas restrições estabelecidas para custo, prazo e desempenho. Segundo Modarres (2006) o termo risco significa não somente a ocorrência de um evento indesejável, mas também quão provável e quais as conseqüências caso ocorra.

O pensamento do gerenciamento de riscos apresenta, complementarmente, alternativas para que tais eventos enquadrados até aqui possam ser administrados. No entanto, para Raz et al (2002) a disciplina gerenciamento de riscos estaria, ainda, em sua infância.

Vários trabalhos (PMI, 2004; VALERIANO, 1998; KEELLING, 2006) têm apresentado o gerenciamento de riscos como uma série de processos interligados envolvendo técnicas e ferramentas específicas. O PMI (2004) propôs seis processos de gerenciamento de riscos: planejamento do gerenciamento dos riscos, identificação, avaliação qualitativa, avaliação quantitativa, respostas ao risco e acompanhamento e controle.

O desenvolvimento e a aplicação de uma metodologia de gerenciamento de riscos em projetos de manutenção de navios, objeto deste trabalho, ainda não foram abordados pela literatura especializada no assunto. Cabe, portanto explorar os conceitos e características deste tipo de projeto.

De acordo com a Sistemática de Acompanhamento Econômico de Projetos da Transpetro (TRANSPETRO, 2000) um projeto de manutenção de navios é um evento de suma importância para sua vida operacional e ocorre por força de cumprimento de normas e regulamentos a cada dois anos e meio, sendo uma manutenção intermediária e uma de fechamento de ciclo a cada cinco anos. A data limite para o término de cada projeto está definida no certificado de cada navio, portanto, a não ser que ocorra algum acidente, ou que haja alguma recomendação ou restrição técnica, o planejamento deve se basear nessas datas.

Em linhas gerais, manter um navio petroleiro significa colocá-lo na doca ou dique (locais que servem para construção ou reparo de navios) fazer os reparos necessários e disponibilizá-lo novamente para uso. Esse processo na área naval é conhecido por docagem. Santos e Gonçalves (2006) explicam que, sob o ponto de vista da operadora, a manutenção pode ser dividida em quatro etapas: preparação da especificação dos reparos, fiscalização e aceitação dos serviços executados, aprovação da fatura do estaleiro e preparação do relatório final do projeto. Manutenção de navios petroleiros, assim, é uma designação genérica do período no qual o navio é entregue a algum estaleiro para fins de reparos (TRANSPETRO, 2002).

Por ocasião destes projetos efetuam-se intervenções e os reparos que não puderam ser feitos durante o ciclo de operações do navio. Isso pode ter ocorrido por não ter havido tempo disponível ou pela necessidade de uma preparação especial de limpeza e eliminação de gases de hidrocarbonetos, utilizados em sistemas vitais do navio, que causariam a sua paralisação. Essa preparação especial permite o trabalho em ambiente saudável para as pessoas, chamadas de "free for fire" ou "free for man".

A identificação dos serviços a serem efetuados, e a definição do estaleiro reparador devem ser feitos anteriormente à retirada do navio de operação e fazem parte da etapa de planejamento do projeto. Esta etapa é complexa, pois para que se obtenha sucesso na execução é necessário negociar a retirada da operação do navio com todos os interessados, conciliando todas as conseqüências oriundas dessa desativação. Também é necessário identificar todos os serviços 
que serão executados, bem como os estaleiros capazes de atender aos requisitos.

A retirada de um navio de operação irá afetar a programação do restante da frota, algumas vezes obrigando a reposição temporária desse equipamento que nem sempre existe disponível no mercado. A correta identificação dos serviços também é prejudicada, pois como o navio está em pleno funcionamento, não é possível a realização de uma inspeção detalhada em todo o navio. Por fim, o estaleiro escolhido pode não receber ou postergar o recebimento, se o navio não estiver disponível para a manutenção na data acordada, pois normalmente a demanda pelos serviços do estaleiro, é maior do que a oferta.

Neste sentido, a atenção à análise de riscos de um empreendimento de manutenção deve levar em conta os aspectos de análise e respostas aos riscos como elemento que poderá subsidiar o executivo em suas decisões (MODICA, 2009).

\section{Aspectos metodológicos}

Para atender os objetivos traçados neste artigo e refletidos na questão de pesquisa (como a estruturação de respostas a riscos relevantes em projetos de manutenção de navios petroleiros pode subsidiar a decisão de seus executivos?) utilizou-se o estudo do tipo exploratório, já que o fenômeno não é conhecido, e como método de pesquisa, o estudo de caso.

Para Yin (1994), três condições determinam o tipo de estratégia de pesquisa a ser utilizada: o tipo de questão a ser respondida, o nível de controle que o pesquisador possui sobre os eventos a serem pesquisados e o nível de foco no fenômeno contemporâneo, em oposição ao fenômeno histórico. Ele também sugere que o estudo de caso deve ser a estratégia adotada quando as questões a serem respondidas são do tipo "como" ou "por que", quando o pesquisador possui pouco controle sobre os eventos a serem investigados e quando o foco está em um fenômeno contemporâneo inserido em um contexto na vida real, especialmente quando as fronteiras entre o fenômeno e o contexto não está claramente evidente. Uma das vantagens da utilização desta estratégia de pesquisa é que, segundo Yin (1994): “Em poucas palavras, o estudo de caso permite à pesquisa manter as características holísticas e mais significativas de eventos da vida real (...)".

Visando entender o fenômeno da administração das incertezas em projetos de manutenção de navio petroleiros, este estudo de caso estabeleceu uma série de procedimentos metodológicos que podem ser desmembrados em quatro fases, descritas a seguir:

Primeira fase

A partir da revisão da literatura teórica em gerenciamento de projetos com ênfase em gerenciamento de riscos, deu-se início ao entendimento da organização, caso objeto deste estudo. Para isto foram realizadas visitas técnicas, feitas entrevistas com gerentes e examinadas informações documentais.

\section{Segunda fase}

Deu-se início ao desenvolvimento do processo de identificação e avaliação de eventos de riscos. Nesta fase os autores participaram do processo e puderam entrevistar os profissionais especialistas em gerenciamento de riscos para examinar a lista de riscos identificados. Após as entrevistas, ainda nesta fase foi possível desenhar a matriz de risco (PMI, 2004) envolvendo opiniões sobre de impacto e probabilidade. Para o estabelecimento das avaliações foram atribuídas notas de 1 a 9 de impacto e probabilidade. E, para a consolidação das avaliações foi utilizada a 
média geométrica para evitar o fenômeno do que Fischhoff et al (1978) chamaram de influências por eventuais valores extremos.

\section{Terceira fase}

Uma vez avaliados e priorizados os eventos de riscos, foi possível desenvolver uma análise cruzada pelo uso da técnica risk-by-risk. Nesta análise, os autores questionaram os especialistas em riscos de docagem, buscando informações para que pudessem entender a composição da lista final. Procedeu-se, assim o alinhamento entre as opiniões dos especialistas e, para isto utilizou-se o coeficiente de correlação de Kendall (MARKOWITSH; SCHMIDT, 1997; CONOVER, 1980; SIEGEL; CASTELLAN, 2006; MARTINS, 2001). Okoli e Pawlowski (2004) afirmam que há diferentes formas de medir priorizações, mas o coeficiente de concordância de Kendall (W) é amplamente reconhecido como o melhor.

A International Maritime Organization (2002) e Kontovas (2005) propõem a utilização sistemática desse coeficiente por ocasião de estudos de riscos de acidentes com embarcações.

O teste estatístico W, chamado de coeficiente de concordância de Kendall, foi apresentado independentemente por Kendall \& Babington-Smith e Wallis em 1939 (CONOVER, 1980), e mede a distância entre as opiniões (KONTOVAS, 2005).

Para calcular o coeficiente $\mathrm{W}$, onde $\mathrm{k}$ especialistas priorizam $\mathrm{N}$ riscos, utilizando números naturais que variam de 1 a $\mathrm{N}$, utiliza-se a seguinte fórmula, onde $\mathrm{Rj}$ é a soma dos postos de cada item avaliado, em uma matriz $\mathrm{k}$ por $\mathrm{N}$ :

$$
W=\frac{\sum\left(R_{j}-\frac{\sum R_{j}}{N}\right)^{2}}{\frac{1}{12} k^{2}\left(N^{3}-N\right)}
$$

A diferença entre cada $\mathrm{Rj}$ e a soma dos $\mathrm{Rj}$ dividida por $\mathrm{N}$ pode ser considerada como o desvio a partir da média. O numerador é a soma dos quadrados dos desvios, e varia de zero ao valor máximo possível que ocorreria no caso de concordância perfeita entre os $\mathrm{k}$ conjuntos de postos, neste caso, igual ao denominador, razão pela qual W varia somente entre zero e um.

De acordo com Conover (1980), se houver perfeita concordância entre as priorizações, ou seja, se todas as priorizações forem exatamente iguais, o resultado do coeficiente $W$ é 1 ; se houver perfeita discordância, ou discordância total entre as priorizações, o coeficiente W será zero ou próximo de zero.

Okoli e Pawlowski (2004) informam que há uma forte concordância entre as opiniões expressas pelos especialistas, caso W apresente valores acima de 0,7. Schmidt (1997) apresentou a Tabela 1 com a interpretação dos valores de W, que mostra também uma forte concordância para valores acima de 0,7. A International Maritime Organization (2006) e Kontovas (2005) afirmam que, para valores de $\mathrm{W}$ acima de 0,7 , tem-se uma boa concordância. A Tabela 2 apresenta os níveis de concordância sugeridos pela International Maritime Organization (2006), de acordo com os valores do coeficiente $\mathrm{W}$.

Tabela 1 - Interpretação do coeficiente de Kendall

\begin{tabular}{|c|c|c|}
\hline $\begin{array}{c}\text { Interpretação do coe- } \\
\text { ficiente de Kendall } \boldsymbol{W}\end{array}$ & Interpretação & Confiança na priorização \\
\hline 0,1 & Concordância muito fraca & Não há \\
\hline
\end{tabular}




\begin{tabular}{|c|c|c|}
\hline $\begin{array}{c}\text { Interpretação do coe- } \\
\text { ficiente de KendallW }\end{array}$ & Interpretação & Confiança na priorização \\
\hline 0,3 & Concordância fraca & Baixa \\
\hline 0,5 & Concordância média & Moderada \\
\hline 0,7 & Concordância forte & Alta \\
\hline 0,9 & Concordância forte (não usual) & Muito alta \\
\hline
\end{tabular}

Fonte: Schmidt (1997).

Tabela 2 - Interpretação do coeficiente de Kendall

\begin{tabular}{|c|c|}
\hline \multicolumn{2}{|c|}{ Coeficiente de concordância } \\
\hline $\mathrm{W}>0,7$ & Boa concordância \\
\hline $0,5<\mathrm{W}<0,7$ & Média concordância \\
\hline $\mathrm{W}<0,5$ & Pobre concordância \\
\hline
\end{tabular}

Fonte: Schmidt (1997).

As priorizações feitas pelos especialistas, tabela 3, foram submetidas ao teste estatístico para determinar-se o coeficiente de alinhamento de Kendall. O resultado encontrado foi 0,731 que de acordo com a International Maritime Organization (2002) significa um nível de concordância bom e de acordo com Schmidt (1997) há uma forte concordância e alta confiança na priorização.

\section{Quarta fase}

Fechamento do processo de pesquisa em que as considerações finais foram estabelecidas. Baseado nestas informações, um relatório final foi gerado e apresentado aos membros da organização estudada contendo as conclusões do estudo, bem como suas recomendações.

\section{Apresentação dos resultados}

O caso deste estudo foi delineado na Transpetro, empresa que faz parte do sistema petrolífero brasileiro, mais especificamente em transporte e armazenagem de petróleo e seus derivados. A empresa opera uma frota de 55 navios com capacidade de transporte de 2,9 milhões de toneladas de porte bruto, $7.033 \mathrm{~km}$ de oleodutos e $3.600 \mathrm{~km}$ de gasodutos, 20 terminais terrestres e 26 terminais aquaviários. Sua capacidade de armazenamento é de 10,3 milhões de $\mathrm{m}^{3}$ de petróleo, derivados e álcool e a capacidade de processamento de gás natural é de 15 milhões de $\mathrm{m}^{3} / \mathrm{dia}$. A carga movimentada na área de dutos em 2007 foi 671 milhões de $\mathrm{m}^{3} / a n o$ de petróleo e derivados e 35 milhões de $\mathrm{m}^{3} /$ dia de gás natural, e a média de navios operados nos terminais foi de 413 por mês. A receita operacional líquida foi de $R \$ 3,446$ bilhões e o lucro líquido foi $R \$ 342,6$ milhões.

A análise nos dados de projetos de docagem foi realizada a partir de uma estrutura analítica de projetos genérica tendo como primeiro nível de decomposição os entregáveis que representam o ciclo de vida do projeto: lista de reparos, especificação técnica dos serviços, contratação do estaleiro, preparo de navio para docagem; docagem e pós docagem.

De posse dessa estrutura foi efetuada a identificação dos eventos de risco, utilizando-se a técnica brainstorming com quatorze especialistas. Os 75 eventos de riscos identificados foram organizados em uma estrutura analítica de riscos obedecendo à seguinte decomposição: riscos de segurança, meio-ambiente e saúde ocupacional, riscos técnicos, riscos externos à operadora, riscos organizacionais e riscos de gerenciamento.

Em seguida, para determinar as probabilidades e impactos de cada evento de risco, foi apli- 
cado um questionário em entrevistas individuais, nas quais participaram seis especialistas. Tratou-se de uma avaliação sobre impactos em docagens e classificação da importância destes eventos.

O resultado da avaliação pode ser visto na Figura 1 em que são mostradas as quantidades de eventos de riscos em função de sua magnitude.

Foi possível notar, por exemplo, que os setenta e cinco eventos tiveram uma distribuição de avaliações entre 3 a 39. Sendo que, grande parte deles (48\%), ou seja, 36 eventos de riscos se concentraram entre avaliações distribuídas de 8 a 14 .

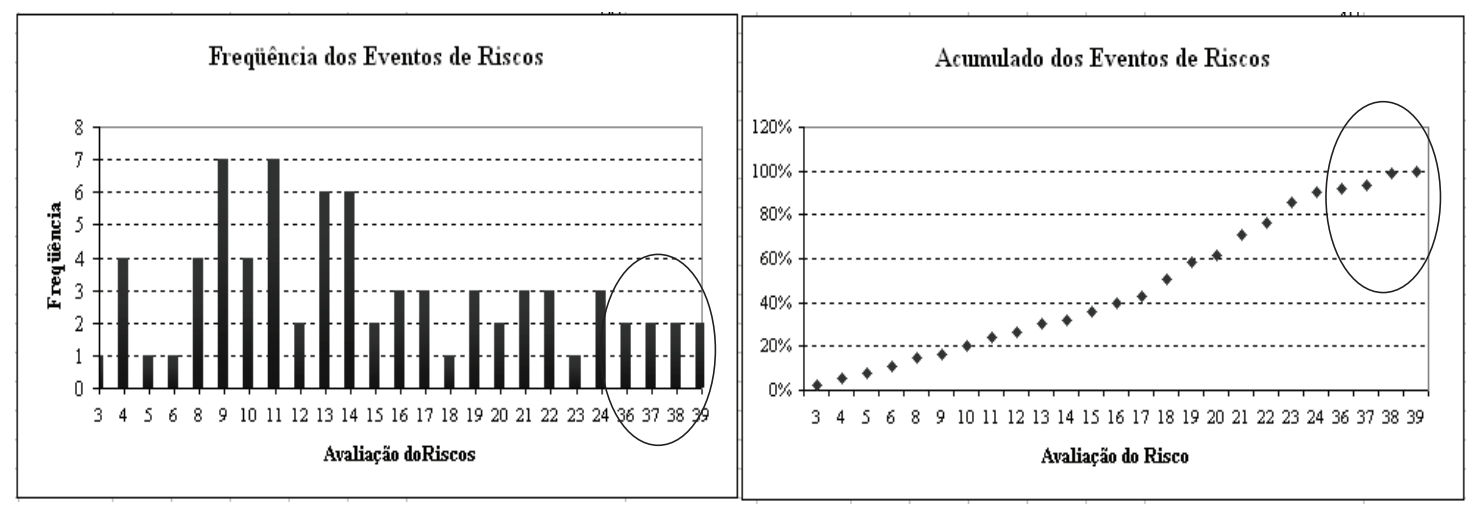

Figura 1 - Avaliação dos Eventos de Risco por Freqüência e Acumulado

Fonte-Autores: pesquisa de campo

Nota-se que há um grupo de eventos de risco destacados dos demais, indicando claramente um ponto de corte para uma classificação: são os oito eventos de riscos que obtiveram avaliação acima de trinta e seis e foram classificados como altos.

Os 75 eventos de riscos puderam ser agrupados em cinco categorias: externo, gerenciamento, organizacional, SMS (saúde, meio ambiente e segurança) e técnico. Os riscos externos e técnicos foram aqueles que apresentaram avaliações de maior intensidade (Tabela 3).

Tabela 3 - Classificação dos eventos de risco

\begin{tabular}{|c|c|c|c|c|c|c|}
\hline Classificação & Externo & Gerenciamento & Organizacional & SMS & Técnico & $\begin{array}{c}\text { Total } \\
\text { geral }\end{array}$ \\
\hline Alto & 3 & 1 & & 1 & 3 & 8 \\
\hline Médio & 17 & 2 & 9 & 2 & 6 & 36 \\
\hline Baixo & 18 & & 7 & 4 & 2 & 31 \\
\hline Total geral & 38 & 3 & 16 & 7 & 11 & 75 \\
\hline
\end{tabular}

Fonte - Pesquisa de campo

Os oito eventos de risco mais intensos, classificados como alto foram:

- Atraso na execução dos serviços por motivos climáticos (externo);

- Especificação técnica deficiente do contrato (técnico);

- Empresa contratada não cumprir o prazo acordado (externo);

- Falta de mão-de-obra qualificada (externo);

- Falhas no cumprimento da programação (gerenciamento);

- Estimativa errada de reparos estruturais (técnico);

- Acidentes de trabalho no estaleiro (SMS);

- Estimativa errada de serviços em tanques (técnico). 
Uma vez selecionados estes oito principais eventos de risco, os autores organizaram uma nova rodada de entrevistas com sete especialistas visando aprimorar e entender a profundidade de cada evento (Tabela 4). As priorizações feitas pelos especialistas foram submetidas ao teste estatístico para determinar-se o coeficiente de alinhamento de Kendall. O resultado encontrado foi 0,731 que de acordo com a International Maritime Organization (2002) significa um nível de concordância bom e de acordo com Schmidt (1997) há uma forte concordância e alta confiança na priorização.

Como resultado desta nova rodada de avaliação foi possível perceber que o evento de risco - atraso na execução dos serviços por motivos climáticos - apresentou a maior intensidade, ou o mais importante entre os oito eventos e, que a estimativa errada de serviços em tanques, a menor nota, sendo assim, o de menor importância.

Tabela 4 - Priorização dos eventos classificados como alto

\begin{tabular}{|c|c|c|c|c|c|c|c|c|}
\hline \multicolumn{3}{|c|}{ Evento de risco } & \multicolumn{5}{c|}{ Especialista } \\
\hline Item & Descrição & $\mathbf{1}$ & $\mathbf{2}$ & $\mathbf{3}$ & $\mathbf{4}$ & $\mathbf{5}$ & $\mathbf{6}$ & $\mathbf{7}$ \\
\hline 1 & Atraso na execução dos serviços por motivos climáticos & 5 & 6 & 7 & 7 & $\mathbf{7}$ & 6 & 6 \\
\hline 2 & Especificação técnica deficiente do contrato & 7 & 7 & 1 & 3 & 3 & 4 & 3 \\
\hline 3 & Contratada não cumprir o prazo acordado & 1 & 1 & 2 & 1 & 5 & 3 & 4 \\
\hline 4 & Falta de mão de obra qualificada & 3 & 4 & 4 & 6 & 2 & 2 & 2 \\
\hline 5 & Falhas no cumprimento da programação & 4 & 5 & 6 & 5 & 6 & 7 & 7 \\
\hline 6 & Estimativa errada de reparos estruturais & 2 & 2 & 3 & 2 & 1 & 1 & 1 \\
\hline 7 & Acidentes de trabalho no estaleiro & 8 & 8 & 8 & 8 & 8 & 8 & 8 \\
\hline 8 & Estimativa errada de serviços em tanques & 6 & 3 & 5 & 4 & 4 & 5 & 5 \\
\hline
\end{tabular}

Fonte - Autores: pesquisa de campo

\section{Análise dos resultados}

A análise dos dados será estruturada considerando-se, para cada risco priorizado, três dimensões. A primeira consistirá de uma apresentação conceitual do evento de risco, em que serão explorados os aspectos úteis para o entendimento de sua natureza. Outra abordará as dificuldades envolvidas nas causas e efeitos relacionadas aos eventos de risco. E, a última, discutirá as considerações sobre os possíveis desdobramentos que poderão remeter ao encaminhamento das respostas aos riscos.

O evento de risco percebido como o mais importante para os especialistas foi o risco 6 - estimativa errada de reparos estruturais. Este evento de risco se refere, especificamente, aos desgastes ocorridos na estrutura do navio, devido o contato de seus componentes com o ambiente náutico. Obviamente, os desgastes na estrutura de um navio precisam ser reparados, pois podem impactar negativamente em todos os projetos nos quais o navio seja um recurso.

As dificuldades inerentes às inspeções de reparos estruturais num navio ocorrem, tanto pela dinâmica do transporte em que ele está envolvido, quanto por restrições técnicas impostas pelo acesso às áreas de reparo. O planejamento do reparo, neste sentido, é cercado de várias incertezas, dificultando as estimativas supostas pelos especialistas. Esta dificuldade pode ser enquadrada ao que Meyer et al (2002) declararam ser incertezas imprevisíveis, pois, há um ou mais fatores significativos que influenciam o projeto que não podem ser previstos.

Ademais, a dificuldade encontrada para estimar a intensidade de reparos, segundo declaração de um dos entrevistados (entrevistado 1) concentra-se no fato do navio não parar para 
ser inspecionado, e assim, as estimativas de quantidades de serviços necessários ficam comprometidas, e segundo ele, "mesmo parando, o acesso às partes afetadas nem sempre é possível, e por ocasião da execução dos reparos descobre-se que a extensão dos serviços é muito diferente da efetivamente contratada".

Por ser o evento de risco mais evidente encontrado neste trabalho, acredita-se que, além de estimativas incorretas sobre a programação de reparos, outros fatores podem influenciar tais dificuldades (MEYER et al. 2002). Nesta linha de raciocínio, alinhado às dificuldades inerentes a este evento de risco, sabe-se, também, que as estimativas podem ser imprecisas devido à falta de informação sobre quantidade e qualidade dos recursos envolvidos no projeto e mesmo indisponibilidade de tais recursos. Por sua vez, tais dificuldades podem, evidentemente, gerar falhas na programação.

A análise nas questões raízes envolvida neste tipo de eventos poderá ajudar os gerentes de riscos em projetos a apontar suas possíveis soluções.

O evento de risco percebido como o segundo mais importante para os especialistas foi o risco 3 - contratada não cumprir o prazo acordado. Este risco está diretamente relacionado com a capacidade das empresas contratadas, ou seja, os estaleiros, em adequar os seus recursos para realizar os serviços contratados, principalmente os recursos de mão-de-obra. Este é um evento com maior probabilidade de ocorrer em empresas, atuando no território nacional, pois elas encontram dificuldades em contratar mão-de-obra necessária para atender os serviços não previstos no contrato, que não haviam sido programados, e para atender múltiplas demandas simultâneas de diferentes clientes quando há picos de serviços. Além da falta de oferta, o regime trabalhista brasileiro dificulta contratações temporárias e onera regimes de trabalho de turno, razão pela qual os estaleiros preferem trabalhar em regime administrativo, perdendo competitividade em termos de prazo, quando comparados aos estaleiros do exterior. Pode ainda haver interesses das empresas em deslocar profissionais para atender serviços objeto de contratos mais atrativos, desfalcando a equipe original prevista para a docagem.

De acordo com o entrevistado 1: "no exterior as empresas têm facilidade para contratar trabalhadores, pois há uma oferta abundante de mão-de-obra qualificada disponível além de regimes trabalhistas mais flexíveis e melhores adaptados à dinâmica de contratações características desse segmento de negócios".

O evento de risco 4 - falta de mão-de-obra qualificada, foi o terceiro classificado. Tem sua causa a paralisação dos serviços de construção naval ocorrida no Brasil durante os últimos anos. Isto contribuiu para a estagnação da mão-de-obra qualificada acarretando um esvaziamento da oferta desses profissionais. De acordo com o entrevistado 1 , quando cessaram as atividades de construção de grandes embarcações no Brasil, as faculdades deixaram de formar engenheiros navais, pois não havia interesse dos estudantes nessa área por não haver mercado de trabalho.

Isto pode ser verificado no que Wideman (1992) chamou de inter-relações entre áreas de conhecimento. No caso risco com recursos humanos, em que as incertezas são pontuadas por produtividade, qualificação de mão-de-obra, disponibilidade de recursos, entre outras.

Em quarto lugar ficou o risco 8 - estimativa errada de serviços em tanque. Este evento se refere aos reparos necessários nos tanques de transporte e armazenamento de petróleo e seus derivados, e nos tanques de lastro do navio, devido ao desgaste interno imposto por esses produtos na pintura, chapas e estrutura metálicas, e externamente devido à ação agressiva do ambiente marinho.

O conhecimento da extensão desses danos, necessário para a correta previsão dos serviços a serem contratados, se torna difícil de ser obtido pelo mesmo motivo explicitado no evento 
de risco número 6, acrescido por:

- A equipe de inspeção não consegue acessar as partes elevadas dos tanques, pela falta de um equipamento para posicionar a equipe de inspeção;

- Nem todos os portos têm disponibilidade para receber os resíduos oleosos, por ocasião da limpeza dos tanques para serem inspecionados;

- Pode não haver disponibilidade de empresas especializadas em serviços de limpeza de tanques na época propícia.

Este evento de risco se enquadra na tipologia proposta por Meyer, et al (2002) como sendo de incertezas previsíveis, onde um evento pode impactar um projeto de forma imprevisível, sendo possível, no entanto, estabelecer planos de contingência para mitigar suas conseqüências caso ocorra.

A quinta classificação foi designada ao evento de risco 2 - especificação técnica deficiente do contrato, que se refere à parte do contrato cujo conteúdo detalha os serviços a serem realizados e, cujas falhas implicarão em problemas na fase de execução dos mesmos. Como, exemplo, pode ser citado o caso das omissões de serviços essenciais. Quando isso ocorre, ou, certamente o navio não receberá os serviços, ou haverá aumento do escopo com conseqüente revisão nas cláusulas contratuais. Este é um caso típico da classificação de Meyer, et al. (2002), para incerteza imprevisível, onde fatores desconhecidos podem afetar o projeto, obrigando a equipe do projeto a resolver o problema à medida que ele se apresente.

Uma especificação técnica poderá ser afetada pela:

- Indisponibilidade de relatórios de inspeção, detalhados sobre a situação do navio para prever a quantidade de serviços necessários, que pode implicar em especificações técnicas superestimando ou subestimando as quantidades de serviços, o que poderá afetar a capacidade de resposta do estaleiro, na fase da execução, tanto para a redução dos serviços programados, quanto para o acréscimo dos serviços necessários, principalmente em estaleiros no Brasil;

- Pouco tempo disponível para elaboração. Planejamentos com prazos muito curtos poderão implicar em especificações sem qualidade, ou concluídas fora do prazo programado, podendo impactar os objetivos da docagem, em termos de custo, prazo e qualidade;

- Especificação incorreta, como por exemplo, ao indicar a substituição de um equipamento cujo fabricante não atua mais no mercado obrigando a aquisição de um similar. Na fase de montagem poderão ser verificados detalhes do equipamento, ou de montagem, que não foram observados na época da especificação, que dificultem a sua aplicação. $O$ entrevistado 1 informou que em uma docagem foi necessário trocar um dos três geradores, porém de marca diferente por não haver disponibilidade de modelo igual no mercado, e, durante a instalação, verificou-se que os cabos elétricos se conectavam em lado oposto do gerador existente, e os cabos não alcançavam a conexão. Como não havia sido prevista a aquisição de cabos, optou-se por fazer um remanejamento de cabos entre os três geradores causando atrasos na conclusão dos serviços;

- Estimativa de preço dos serviços equivocada, impactando na contratação das empresas e podendo acarretar atrasos no projeto. De acordo com o entrevistado 3, "esta é uma situação muito rara, mas acontece";

- Avaliação errônea de algumas aquisições para o projeto, como, por exemplo, atri- 
buir para o estaleiro a responsabilidade sobre o fornecimento de equipamentos com prazos longos para o fornecimento, inviabilizando a sua aquisição na fase de execução dos serviços;

- Informações equivocadas sobre a vida útil do navio, acarretando em execução de serviços que poderiam ser dispensados, pois o navio seria alienado.

Em sexto lugar ficou o risco 5 - falhas no cumprimento da programação, que se refere ao longo prazo necessário para o processo de licitação e contratação dos serviços de reparos. Quando isso ocorre, dificulta a correta previsão da situação de operação do navio na época prevista de parada de docagem. Se houver necessidades de ajustes, elas serão dificultadas pela alta taxa de utilização dos navios. O entrevistado 1, neste caso, informou que, "embora tenhamos um planejamento de parada dos navios previamente acertado com a área responsável pela programação da Petrobras, na ocasião da parada sempre há pedidos de alterações de datas".

Tem sido verificada uma taxa de $30 \%$ de alterações de datas de retirada do navio de operação, impactando tanto a operadora quanto o estaleiro que se prepara para receber o navio, atendendo ao estipulado no contrato.

O sétimo lugar em ordem de importância, o risco de número 1 - atraso na execução dos serviços por motivos climáticos se refere a atrasos em função de condições climáticas muito desfavoráveis, que podem afetar a qualidade dos serviços e o desempenho dos trabalhadores. $\mathrm{Na}$ verdade, este risco, em essência, deveria ser nomeado como: ocorrência de motivos climáticos desfavoráveis, pois o atraso, na verdade, seria sua conseqüência natural da impossibilidade da execução dos serviços ou pela diminuição do ritmo de trabalho planejado.

A incidência deste risco pode ocorrer, por exemplo, na ocasião de uma pintura. Este serviço tem seu resultado comprometido quando a umidade relativa do ar for superior a $85 \%$, índice que é ultrapassado por ocasião de chuvas e de baixas temperaturas que ocorrem freqüentemente nos meses de junho e julho no Brasil. Esse índice também é superado nos estaleiros da Argentina durante o período do inverno, devido à baixa temperatura formar gotículas nas chapas metálicas.

Condições climáticas desfavoráveis também são encontradas nos estaleiros do Reino do Bahrein durante o verão. Segundo o especialista 5, que recentemente havia acompanhado uma docagem nesse local, "às sete horas da manhã a temperatura é de 45 으, mas com sensação térmica muito superior dentro dos tanques dos petroleiros, prejudicando o desempenho dos trabalhadores".

Os estaleiros da Coréia do Sul também são prejudicados pelas condições climáticas, tendo um frio intenso nos meses de dezembro e janeiro e tufões nos meses de julho e agosto, conforme informou o especialista 1.

O risco de menor importância foi o de número 7 - acidentes de trabalho no estaleiro, que se refere a acidentes que podem causar danos aos trabalhadores, ao meio-ambiente, aos materiais e equipamentos. A preocupação com a ocorrência deste evento de risco despertou, na empresa estudada neste caso, o desencadeamento de ações políticas na direção de organização dos aspectos de saúde dos trabalhadores e da preservação do meio-ambiente. Tais ações foram desenvolvidas mesmo sabendo-se que, estes eventos de risco possam impactar pouco nos objetivos do projeto em termos de prazo, custo e qualidade.

Uma vez analisados os riscos, procurou-se, para fechar a argumentação desta análise, estudar o relacionamento entre esses eventos de risco, verificando-se as relações existentes entre eles. Para consolidar tal análise uma matriz de relacionamento expressa na Figura 2, foi 
construída. Nesta matriz, tanto nas linhas quanto nas colunas foram enumerados os oito riscos. Nas células puderam-se identificar os relacionamentos. O evento número quatro, por exemplo, impacta os eventos dois, três, cinco, seis, sete e oito. Já o evento seis impacta somente os eventos dois e três.

\begin{tabular}{|c|c|c|c|c|c|c|c|c|c|}
\hline \multicolumn{10}{|c|}{ Eventos que são impactados } \\
\hline \multirow{9}{*}{$\begin{array}{l}\text { Eventos que } \\
\text { impactam }\end{array}$} & & 1 & 2 & 3 & 4 & 5 & 6 & 7 & 8 \\
\hline & 1 & & Fraco & Sim & Não & Fraco & Fraco & Fraco & Fraco \\
\hline & 2 & Não & & Sim & Não & Sim & Não & Não & Não \\
\hline & 3 & Não & Sim & & Não & Sim & Não & Fraco & Não \\
\hline & 4 & Não & Sim & Sim & & Sim & Sim & Sim & Sim \\
\hline & 5 & Não & Não & Sim & Não & & Não & Não & Não \\
\hline & 6 & Não & Sim & Sim & Não & Não & & Não & Não \\
\hline & 7 & Não & Não & Sim & Não & Não & Não & & Não \\
\hline & 8 & Não & Sim & Sim & Não & Não & Não & Não & \\
\hline
\end{tabular}

Figura 2 - Matriz de relacionamento dos eventos de risco

Fonte - Autores: pesquisa de campo

Foi possível observar que o risco 1 - atraso na execução dos serviços por motivos climáticos apresenta uma relação com os eventos dois, três, cinco, seis, sete e oito. O clima desfavorável pode impactar com baixa intensidade os eventos de estimativa de serviços, pois pode prejudicar o trabaIho da equipe de inspeção. Dessa forma pode impactar na especificação técnica dos serviços, que se baseia nos relatórios da inspeção. Nessa linha de raciocínio é possível notar que esse evento de risco pode impactar, também, com fraca intensidade, na ocorrência de acidente no estaleiro, seja no calor intenso, com trabalhadores podendo passar mal, ou em tempestades, com possíveis acidentes envolvendo materiais, equipamentos e pessoas. O risco 1 assim contribui, também, fortemente, com o atraso na execução dos serviços, nas ocasiões em que paralisa os trabalhos nos estaleiros durante as tempestades e impede a pintura devido à alta taxa de umidade no ar.

Como alternativa de respostas a eventos de riscos deste tipo identificou-se que a operadora poderia optar por não escolher os estaleiros que estejam em condições climáticas desfavoráveis na época da docagem, desde que essa ação não prejudique o relacionamento comercial com essas empresas. Outra opção seria evitar docar o navio em épocas desfavoráveis.

O evento 2 - especificação técnica deficiente impacta fortemente o cumprimento do prazo pela contratada (risco 3), pois implica na necessidade da adequação do planejamento por parte do estaleiro, que pode demandar tempo adicional para adequar seus recursos sejam de materiais, equipamentos ou mão-de-obra. Também pode impactar no cumprimento da programação (risco 5), uma vez que, ao demandar tempo extra para ser feito, reflete o atraso em todo o processo de contratação do estaleiro.

A contratada não cumprir o prazo acordado, evento 3 , quando se referir às empresas de inspeção, impacta no prazo de elaboração da especificação técnica, que depende dos relatórios de inspeção, e pode impactar no cumprimento da programação se estiver no caminho crítico do projeto. Pode, ainda, contribuir, mesmo que com baixa intensidade, na ocorrência de acidentes no estaleiro, uma vez que a contratada ao se deparar com atrasos de cronograma pode tentar acelerar os seus processos negligenciando aspectos de segurança. 
O histórico das docagens indica quais são os estaleiros e outras empresas que obtêm mais sucesso no cumprimento deste risco, sendo assim, como alternativa de resposta a operadora poderia direcionar um número maior de docagens para esses estaleiros e empresas. Adicionalmente os contratos poderiam ser mais rigorosos premiando reduções de prazo e aumentando as penalidades para quem não consegue cumprir os compromissos assumidos, excetuando-se os acréscimos de prazo justificados. A operadora poderia também fazer um levantamento detalhado do histórico das docagens para verificar quais as práticas que podem interferir no desempenho dos estaleiros.

O evento 4 falta de mão-de-obra qualificada só não impacta nos atrasos por motivos climáticos, mas influi fortemente na qualidade das inspeções prejudicando as especificações técnicas, e caso essas especificações não sejam elaboradas no prazo previsto, ocorrerá atrasos de programação. A falta de mão-de-obra especializada também pode contribuir para a ocorrência de acidentes e para a baixa produtividade nos estaleiros acarretando em atrasos no projeto.

Para o evento de risco 4, como alternativa de respostas foi identificada a possibilidade de a operadora atuar junto ao mercado nacional, contratando a construção de navios, fomentando a formação de mão-de-obra técnica especializada, e participando de grandes programas de formação de mão-de-obra a nível nacional.

As falhas no cumprimento da programação, evento 5 , podem influir fortemente nos prazos de execução de serviços, principalmente dos estaleiros, uma vez que ao alterar as datas programadas de parada da embarcação, poderá não conseguir adequar os seus recursos de forma ideal para cumprir os prazos contratados.

Como alternativa de resposta a esse tipo de risco foi possível identificar que a operadora poderia diminuir a taxa de utilização das embarcações, pelo aumento da frota, aumentando a possibilidade de conseguir retirar o navio de operação nas datas programadas.

Os eventos 6 e 7, respectivamente, estimativas erradas de reparos estruturais e acidentes de trabalho no estaleiro, em tanques, influem fortemente nas especificações técnicas, seja nos objetivos de qualidade ou nos de prazo, que em conseqüência podem impactar no tempo de execução dos serviços.

Finalmente, o evento 7 - acidentes de trabalho no estaleiro pode impactar, ainda que modestamente, nos prazos acordados para execução dos serviços, pois, segundo o especialista numero 1 , "pode paralisar por algumas horas ou no máximo em um dia os serviços" (Informação verbal).

Para este evento de risco foi possível identificar, como resposta que a operadora pouco pode fazer para mitigá-lo. Quando as docagens forem executadas em estaleiros fora do Brasil; mas em estaleiros nacionais, a operadora pode exigir em seus contratos práticas que valorizem a segurança e exercer o papel de fiscalização no cumprimento dos compromissos assumidos.

De uma forma geral, para reduzir os riscos do projeto de docagem, a operadora poderia minimizar a quantidade de serviços realizados por ocasião da parada, adotando uma política de manutenção que oriente a execução de serviços, possíveis de serem realizados, durante as campanhas no navio.

De forma geral, para os eventos de risco técnico foram identificadas, como alternativas de respostas, que a operadora poderia investir mais no planejamento, parando o navio por alguns dias, para melhorar o trabalho de inspeção. Adicionalmente, ter contratos de longa duração com abrangência internacional para a realização das inspeções e estabelecer um programa de pesquisas correlacionando dados das embarcações, (como idade, tamanho, tipos, produtos transportados, área geográfica de atuação e outros), com os danos constatados por ocasião das docagens, poderiam contribuir para uma melhor previsão dos serviços necessários. 
Para reduzir os riscos do projeto de docagem, também, foi mencionado pelos especialistas que a operadora poderia minimizar a quantidade de serviços realizados por ocasião da parada, adotando uma política de manutenção que oriente a execução de serviços possíveis de serem realizados durante as campanhas no navio.

\section{Conclusão}

Com a análise dos resultados apresentados aqui foi possível entender como é possível, através da estruturação de respostas a riscos relevantes em projetos de manutenção de navios petroleiros, subsidiar a decisão dos executivos. Esta linha conclusiva corrobora com a visão de Akintoye e MacLeod (1997) que realizaram pesquisa na área de engenharia da construção.

Para o desenvolvimento deste caso desenvolveram-se, inicialmente, os procedimentos de identificação de eventos de riscos, para, em seguida, selecionar aqueles que afetam de maneira mais contundente os objetivos do projeto. Complementando as práticas sugeridas pela literatura especializada no assunto, o caso revelou a possibilidade de fazer uso mais intenso de especialistas para se obter resultados qualitativos mais precisos. Por meio de uma classificação feita por tais especialistas foi possível se chegar a oito eventos de riscos considerados mais relevantes, de um total de 75 levantados inicialmente. Por ordem, foram identificados os seguintes eventos riscos: estimativa errada de reparos estruturais, empresa contratada não cumprir o prazo acordado, falta de mão-de-obra qualificada, estimativa errada de serviços em tanque, especificação técnica deficiente do contrato, falhas no cumprimento da programação, atraso na execução dos serviços por motivos climáticos e acidentes de trabalho no estaleiro.

Visando gerar respostas efetivas o trabalho apresentou uma análise em duas dimensões, uma envolvendo cada evento de risco e outra, considerando-se seus relacionamentos. Com isto foi possível sugerir mais uma nova prática complementar aquelas identificadas pela literatura.

Este trabalho teve como resultado um quadro revelador que poderá gerar novas práticas de gerenciamento de riscos em projetos e ou aprimoramento das práticas existentes considerando-se o negócio como elemento relevante de enfoque.

No desenrolar deste trabalho percebeu-se, contudo limitações que impediram a generalização de seus resultados. Entre elas o tipo de estudo; o estudo de caso que, conceitualmente inibe quaisquer extrapolações, bem como o tipo de projeto relacionado ao negócio de docagem de navios petroleiros.

Como sugestões de novos estudos, o que se pode mencionar, a partir destes resultados é a possibilidade de explorar o gerenciamento de riscos em outros tipos de projetos, sendo possível, assim, fazer uma avaliação comparativa. Seria possível ainda adicionar as práticas aqui verificadas e realizar estudos de verificação em vários setores econômicos. 


\section{REFERÊNCIAS}

AKINTOYE, AKINTOLA , S.; MACLEOD, MALCOLM J. Risk analysis and management in Construction. International Journal of Project Management Vol. 15, No. 1, pp. 31-38, 1997

BERNSTEIN, P. L. Desafio aos deuses: a fascinante história do risco. 6. ed. Rio de Janeiro: Campus, 1977.

CARVALHO, M. M.; RABECHINI Jr., R. Construindo Competências para Gerenciar Projetos. Editora Atlas, 2005.

CONOVER, W. J. Practical nonparametric statistics. 2nd. New York: John Wiley \& Sons, 1980.

FISCHHOFF, B.; SLOVIC, P.; LICHTENSTEIN, S. How safe is safe enough? A psychometric study of attitudes towards technological risks and benefits. Policy Sciences. n. 9, p. 127-152, 1978.

HILLSON, D. Extending the Risk Process to Manage Opportunities. Fourth European Project Management Conference, PMI Europe 2001, London UK, 2001

IBBS, C. W.; KWAK, Y. H. Assessing Project Management Maturity. Project Management Journal, v. 31, n. 1, p. 32-43, 2000.

INTERNATIONAL MARITIME ORGANIZATION. Guidelines for formal safety assessment (FSA) for use in the IMO rule-making process. London: IMO, 5 Apr. 2002. (MSC/Circ. 1023; MEPC/Circ. 392).

KEELLING, R. Gestão de projetos: uma abordagem global. São Paulo: Saraiva, 2006.

KONTOVAS, C. A. Formal safety assessment: critical review and future role. 2005. 163p. Thesis (Naval Archicteture and Marine Engineering) - National Technical University of Athens, Maritime Transport, Athens, Greece,2005.
MARKOWITSH, H. J.; PRITZEL, M. Brief Communication - Nonparametric statistic for the analyses of behavior-related single unit data. Physiology \& Behavior, Elmsford, v. 18, p. 717-719, 1977.

MARTINS, G. A. Estatística geral e aplicada. 2. ed. São Paulo: Atlas, 2001.

MEYER, A; LOCH, C. H.; PICH, M. T. Managing Project Uncertainty: From Variation to Chaos. MIT Sloan Management Review, v. 43, n. 2, p. 59-68, winter, 2002.

MODARRES, M. Risk analysis in engineering: techniques, tools, and trends. Boca Raton: Taylor \& Francis Group, 2006.

MODICA, J. E. Riscos em projetos de docagens de navios petroleiros. 2009. 118 p. Dissertação (Mestrado) - Escola Politécnica, Universidade de São Paulo, São Paulo, 2009.

OKOLI, C.; PAWLOWSKI, S. D. The Delphi method as a research tool: an example, design considerations and applications. Information \& Management, Amsterdam, v. 42, p. 15-29, 2004.

PERMINOVA, O.; GUSTAFSSON, M.; WIKSTRÖM, $K$. Defining uncertainty in projects - a new perspective. International Journal of Project Management, n. 26, p. 73-79, 2008.

PMI - PROJECT MANAGEMENT INSTITUTE. Conjunto de Conhecimentos em Gerenciamento de Projetos (PMBOK). 3.ed. EUA: PMI, 2004.

RAZ, T; SHENHAR, A.; DVIR, D. Risk management, project success, and technological uncertainty. R\&D Management, v 32, n 2, 2002.

SANTOS, L. M.;GONÇALVES, N. A. Gestão do Programa de Docagens da Transpetro/ Fronape Comparada às Melhores Práticas de Gerenciamento de Projetos em Termos de Escopo e Tempo. São Paulo, 2006.

SCHMIDT, R. C. Managing Delphi Surveys Using Nonparamatrics Statistical Techniques. 
Decision Sciences, v. 28, n. 3, p. 763-774, 1997.

SALLES JR., C.A.C.; RABECHINI JR., R.; VALLE, J.A.S.; SOLER, AM. Gerenciamento de Riscos em Projetos. Editora FGV, Rio de Janeiro, 2006.

SIEGEL, S.; CASTELLAN N. J. J Estatística nãoparamétrica para ciências do comportamento. 2.ed. Porto Alegre: Artmed, 2006.

TRANSPETRO. Manual de grandes reparos $e$ docagens - SGF/GRD-001. Rio de Janeiro, 2002.

TRANSPETRO. Sistemática de Acompanhamento Econômico de Projetos. Rio de Janeiro, 2000.

UNITED STATES DEPARTMENT OF DEFENSE. Risk management guide for DOD acquisition. 6nd. [S.I.]: DOD, 2006. 40p.

VALERIANO, D L. Gerencia em Projetos Pesquisa, Desenvolvimento e Engenharia. São Paulo: Makron Books, 1998.

WARD, S.; CHAPMAN, C. Transforming project risk management into project uncertainty management. International Journal of Project Management, n. 21, p. 97-105, 2003.

WIDEMAN, R. M. Project and Program risk management: a guide to managing project risks and opportunities. Newtown Square: Project Management Institute, 1992.

YIN, R. K. Estudo de caso: planejamento e métodos. 3. ed. Porto Alegre: Bookman, 2005. 